\title{
Comportamento da taxa Selic no regime de metas de inflação e a paridade descoberta da taxa de juros
}

\author{
Marcelo Curado* \\ Luciano Lara ${ }^{* *}$
}

A discussão sobre a condução da política monetária no regime de metas de inflação, em particular sobre o comportamento da taxa Selic, é um dos temas mais recorrentes do recente debate macroeconômico. Diversos analistas - acadêmicos ou não - argumentam que as taxas de juros definidas pelo Comitê de Política Monetária (COPOM), sobretudo a partir de 2003, são exageradamente elevadas. Não obstante, salvo raras exceções, não há o cuidado de se detalhar o que se entende por uma taxa exageradamente elevada.

Quando trabalhamos com uma economia aberta assume-se, tal como propõe o próprio Banco Central do Brasil em seu modelo econométrico estrutural de previsão de inflação ${ }^{8}$, que a taxa de juros é definida pela chamada paridade descoberta da taxa de juros (UIP). A UIP afirma que o diferencial de juros entre uma economia doméstica e a taxa de juros praticada no mercado internacional deve ser igual à expectativa de desvalorização da moeda local, acrescida do componente de risco país. Podemos expressar a UIP por:

$$
i=i^{*}+E(e)+\theta
$$

Onde: i é a taxa de juros doméstica; i* taxa de juros internacional; E(e) expectativa de desvalorização da moeda e $\theta$ é uma medida de risco-país.

Objetivamente, a UIP afirma que para comprar títulos de uma economia com risco (como a brasileira) os agentes exigem, além da taxa de juros paga por títulos livres de risco, o prêmio de risco, expresso pela soma da expectativa de desvalorização da moeda local e o risco país. A UIP fornece, portanto, uma medida de qual seria a taxa de juros necessária para "convencer" os agentes econômicos a comprarem títulos numa determinada economia. Em tese, se a taxa de juros praticada for inferior a estabelecida pela UIP, os agentes econômicos não adquirem títulos deste país para compor seu portfólio. Por outro lado, se a taxa praticada for superior a estabelecida pela UIP, este país estará pagando além do necessário para compensar o risco dos agentes.

\footnotetext{
* Doutor em Economia pela Universidade de Campinas (UNICAMP). Professor do Departamento de Economia da Universidade Federal do Paraná (UFPR). Endereço eletrônico: mcurado@ufpr.br

** Graduando em Ciências Econômicas pela Universidade Federal do Paraná (UFPR). Bolsista do Programa de Educação Tutorial (PET).

${ }^{8}$ Sobre o modelo estrutural de previsão sobre a inflação veja-se: Bodanski, Tombini \& Velang (2000) e Curado \& Oreiro (2005).
} 
Gráfico 1. Selic vs. i* + var. câmbio + risco país

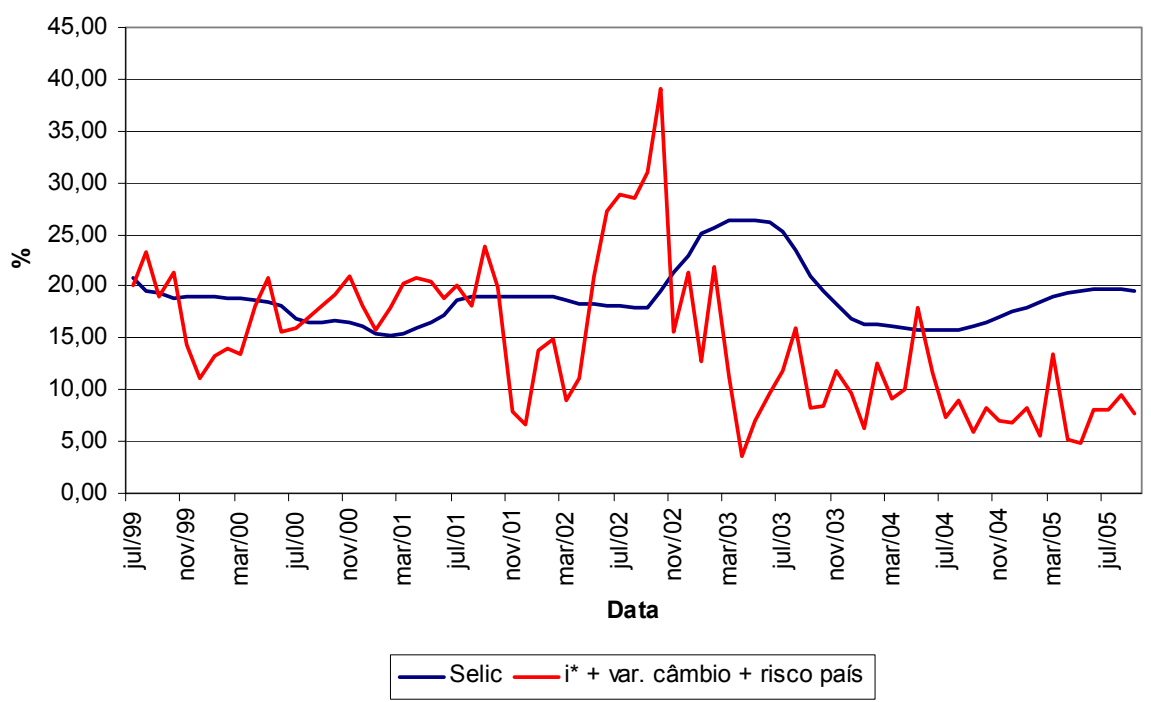

Fonte: BCB, IPEADATA, Federal Reserve, Elaboração Própria.

A análise do gráfico 1, que apresenta uma estimação da UIP e sua comparação com a evolução da taxa Selic ${ }^{9}$, permite algumas conclusões.

Não necessariamente a utilização de um regime de metas de inflação promove como resultado a verificação de uma taxa de juros efetiva superior a taxa de juros de equilíbrio. Entre 1999 e 2002, sobretudo em função das fortes oscilações nas variáveis câmbio e risco país, em diversos momentos a taxa de juros efetiva esteve abaixo da taxa de juros de equilíbrio.

Em particular, a partir de 2003 a política monetária conduzida pelo COPOM tem justificado as críticas relativas ao comportamento da taxa de juros. Em praticamente todo o período (exceto para uma observação) a taxa de juros efetiva tem se mantido acima da taxa de juros estabelecida pela UIP.

Além dos movimentos do câmbio, a redução verificada na taxa de juros de equilíbrio é fruto da drástica redução no componente de risco-país. Pode-se afirmar, neste sentido, que a

\footnotetext{
${ }^{9}$ Como medida da taxa de juros doméstica utiliza-se a taxa de juros Selic definida pelo COPOM. Esta é a taxa que representa de forma mais precisa a condução da política monetária. Como medida da taxa de juros internacional utilizamos a prime rate, em função de sua importância enquanto padrão de referência dos contratos no sistema financeiro internacional. Assumimos que os agentes formam racionalmente suas expectativas e que não existem novidades no sistema. Isto implica assumir que os agentes sempre acertam o alvo, de tal forma que a expectativa em relação ao comportamento da taxa de câmbio é exatamente igual a sua variação efetiva. Um modelo mais sofisticado poderia incorporar uma variável aleatória do tipo ruído branco, porém os resultados na média não seriam afetados já que, por hipótese, variáveis do tipo ruído branco tem média zero. Como medida da percepção de risco país por parte dos agentes utilizamos o spread dos C-Bonds brasileiros. Sobre o modelo estrutural de previsão sobre a inflação veja-se: Bogdanki, Tombini \& Velang (2000) e Curado \& Oreiro (2005).
} 
política monetária conduzida pelo COPOM desde 2003 não tem aproveitado o cenário externo positivo. Em particular, a redução do componente de risco-país não tem promovido uma redução proporcional na taxa de juros de equilíbrio.

Estas considerações permitem chegar a alguns resultados interessantes. Em primeiro lugar, corroborando a maior parte dos estudos sobre o regime de metas de inflação, as evidências sugerem que a instituição do regime não necessariamente obriga a Autoridade Monetária a praticar taxas de juros elevadas (em relação ao patamar estabelecido pela UIP) para alcançar a meta de inflação. As evidências sugerem que a prática de juros exageradamente elevadas resulta da condução específica da política monetária a partir de 2003.

A idéia de que o COPOM tem "exagerado na dose" da política monetária tem sido apresentada em diversos trabalhos e se constitui num dos argumentos centrais daqueles que acreditam na necessidade de ajuste - preservando as conquistas já obtidas - do regime de metas de inflação. Neste sentido, as evidências apresentadas se constituem em mais um argumento na defesa de uma profunda revisão da política monetária atualmente praticada em nosso país.

\section{Referências Bibliográficas}

Bogdanski, J., Tombini, A. \& Verlang, S. R. Implementing inflation targeting in Brazil. Brasília: Banco Central do Brasil, 2000 (working paper, n.1).

Curado, M \& Oreiro, J. L. Metas de Inflação: uma avaliação do caso brasileiro. Indicadores Econômicos FEE (2005). Porto Alegre, v.33, n.2 set., p.127-146. 
